\title{
COVID-19 Severe Pneumonia in Mexico City - First Experience in a Mexican Hospital
}

\author{
Valente-Acosta B, Hoyo-Ulloa I, Espinosa-Aguilar L, Mendoza-Aguilar R, Garcia-Guerrero J, Ontañon-Zurita D, Gomez-Gomez B, \\ Fueyo-Rodríguez O, Vera-Zertuche JM, Anzola-Arias RJ, Jiménez JV, Horta-Carpinteyro D, Olvera-Guzman C, Aguirre-Sanchez \\ J, Franco-Granillo J, Jauregui-Camargo L, Sada-Díaz E, Saavedra-Perez-Salas R, Palomar-Lever A, Ron-Aguirre A and Moreno- \\ Sánchez $\mathrm{F}^{*}$ \\ Centro Médico ABC, Mexico City, México
}

*Corresponding author: Francisco Moreno-Sánchez, Torre de consultorios Mc Kenzie 2-C, Sur 136 No. 116, Col. Las Américas, Álvaro Obregón, 01120, Cd. de México; Tel: 525552731138; E-mail: pacomore@gmail.com

Received: June 11, 2021; Accepted: June 21, 2021; Published: June 26, 2021

\begin{abstract}
Mexico has been widely affected by COVID-19. There are no data describing the epidemiology and treatment of this disease in Mexican population. We conducted a retrospective cohort study of patients with severe or critical COVID-19 pneumonia hospitalized at a third-level care private hospital in Mexico City, from March 13th to April 13th, 2020. A total of 33 hospitalized patients were included, twenty-one patients with severe and 12 with critical COVID-19 pneumonia. The mean age was 60.6 years and $23(70 \%)$ were males. Twenty-three patients (70\%) were overweight or obese. All patients in the critical pneumonia group $(12 / 33,36 \%)$ required mechanical ventilation. The extubation rate was high (92\%) and the mortality was low $(3 \%)$. This is the first case series reported from a middle-income country where only one patient died despite the high prevalence of variables associated with worse prognosis such as obesity and/or chronic medical conditions.
\end{abstract}

Keywords: COVID-19; Coronavirus; Hospital epidemiology

\section{Introduction}

In December 2019, an outbreak of atypical pneumonia was reported in Wuhan, China. Soon after, a novel coronavirus was identified and named severe acute respiratory syndrome coronavirus 2 (SARS-CoV-2) while the disease itself has been worldwide recognised as coronavirus disease 2019 (COVID-19) [1]. As the pandemic evolves, having accurate local and international information has become remarkably important. In the first weeks after the description of cases, the flow of information arose mainly from China and Europe but it rapidly evolved to a World pandemic. While there is no available epidemiological information from Mexico, some characteristics of the Mexican population, such as the Hispanic background and the high rates of obesity, may provide additional valuable information. Both obesity and Hispanic race have been recognised as risk factors for COVID's pneumonia bad outcome [2]. Herein, we described the first case series of hospitalised COVID-19 patients in Mexico City, with special focus on treatment and prognosis.

\section{Methods}

\section{Setting and Study Population}

We conducted a retrospective cohort study of hospitalised patients with severe or critical COVID-19 pneumonia admitted to the American British Cowdray (ABC) Medical Center in Mexico from 13 March to 13 April 2020.All patients were admitted to the Intensive Care Unit (ICU) or the high-dependency unit. The $\mathrm{ABC}$ Medical Center is a tertiarylevel care private hospital in Mexico City with 124 beds, of which 40 correspond to the ICU and high dependency unit. From the beginning of the pandemic, our hospital has been devoted exclusively to the care of COVID-19 patients. The ABC Medical Center has two campuses in Mexico City, the authorities from our hospital decided to convert one campus to COVID-19 only and let one campus free of COVID-19. This decision was made in order to continue providing regular medical care to our patients in a COVID-19 free hospital. In our hospital, only severe and critical pneumonia COVID-19 patients were hospitalised. Critical cases were admitted to the ICU and severe cases to the high dependency unit. Adults were classified, depending on their clinical presentation, in severe or critical pneumonia [3]. We did not have any pregnant women or children admitted with COVID-19 pneumonia.

\section{Data Sources}

We obtained demographic, clinical, laboratory and radiologic data at admission and during the patients' hospitalisation from the electronic health record. The laboratory data and information on the treatment given were collected for all patients up to the time of the data cut, which occurred on 19 April 2020. Data were anonymised before analysis. Informed consent was waived by the ethics committee because all the information in the present work is anonymized. The institutional ethics and research committee approved the protocol (ABC-20-12). 


\section{Study Definitions}

A confirmed case of COVID-19 was defined by a positive result on a reverse transcriptase-polymerase chain reaction (RT-PCR) assay of a specimen collected on a nasopharyngeal swab or a patient presenting with clinical and radiological signs compatible with COVID-19 despite at least two consecutive negative SARS-CoV-2 RT-PCR determinations. Overweight and obesity were defined by the body mass index (BMI), according to World Health Organization, where overweight is considered a BMI greater than or equal to 25 and Obesity a BMI greater than or equal to 30 . We divided patients into two groups according to the Chinese Clinical Guidance for COVID-19 Pneumonia Diagnosis and Treatment [3]:

1. Severe disease was defined as patients presenting with dyspnoea, a respiratory rate of more than $30 / \mathrm{min}$, peripheral capillary oxygen saturation $\left(\mathrm{SpO}_{2}\right)$ of $90 \%$ breathing ambient air and/or a $\mathrm{PaO}_{2} / \mathrm{Fio}_{2}$ ratio less than 231 (in agreement with the Mexico City altitude);

2. Critical disease was defined as severe pneumonia with respiratory failure requiring invasive mechanical ventilation, shock and/or other organ dysfunctions requiring admission to the intensive care unit (ICU). Patients with critical COVID-19 pneumonia had acute respiratory distress syndrome [4].

\section{Specimen Collection and Testing}

Clinical specimens for SARS-CoV-2 diagnostic testing were obtained in accordance with the Center for Disease Control and Prevention guidelines. Different kits targeted the SARS-CoV-2 E-gene and the RdRP gene, including the RN easy Mini Kit (Qiagen), and the Light Cycler II Z480 (Roche ${ }^{\circ}$ ) with Light Mix Modular detection system (TIB Molbiol, Roche) targeted the CoV E-gene, the CoV $\mathrm{N}$-gene and the CoV RdRP gene were employed [5]. Upon hospital admission, routine laboratory tests were performed: complete blood count, and chemistry including electrolytes, liver function tests, C-reactive protein, procalcitonin as well as cardiac enzymes, D-Dimer, ferritin and IL-6 levels. Other tests performed at initial evaluation included: Influenza a virus detection by PCR and respiratory pathogen panel by multiplex PCR. If the patient had a productive cough a sputum sample was sent for bacterial and fungal culture. Regarding imaging studies, a chest CT scan was performed in all but one patient. We could not take a CT scan of this particular patient because it was unsafe to transfer due to hemodynamic instability. Laboratory blood analyses were repeated daily or at physician's discretion. Chest $\mathrm{X}$ ray and EKG were done on a daily basis. All patients who required invasive mechanical ventilation had at least one bronchial aspirate for microbiological analysis, including bacterial and fungal culture as well as galactomannan.

\section{Antiviral, Anti-inflammatory and Antibiotic Treatment}

Treatment was chosen at the attending physician's discretion. Antiviral drugs included one or more of the following options: Lopinavir/ritonavir, hydroxychloroquine, interferon beta- $1 \mathrm{~b}$ and azithromycin. Afterwards, and only for analysis purposes, the patients were classified according to the medications received into the following groups:

1. Lopinavir/ritonavir (LPV/r) $400 \mathrm{mg} / 100 \mathrm{mg}$ twice daily (BID) for 7 days + Interferon beta-1b (IFNb-1b) $0.25 \mathrm{mg}$ every $48 \mathrm{~h}$ for 3 to 7 doses + Azithromycin (AZI) $500 \mathrm{mg}$ initial dose and $250 \mathrm{mg}$ daily for 5 days.

2. $\mathrm{LPV} / \mathrm{r} 400 \mathrm{mg} / 100 \mathrm{mg}$ (BID) for 7 days + IFNb-1b $0.25 \mathrm{mg}$ every $48 \mathrm{~h}$ for 3 to 7 doses + AZI $500 \mathrm{mg}$ initial dose and then $250 \mathrm{mg}$ daily for 5 days + Hydroxychloroquine (HCQ) loading dose of $400 \mathrm{mg}$ BID and then $200 \mathrm{mg}$ BID for 5 to 10 days.

3. $\mathrm{LPV} / \mathrm{r} 400 \mathrm{mg} / 100 \mathrm{mg}$ BID for 7 days + AZI $500 \mathrm{mg}$ initial dose and then $250 \mathrm{mg}$ daily for 5 days + HCQ loading dose of $400 \mathrm{mg}$ BID and then $200 \mathrm{mg}$ BID for 5 to 10 days.

4. AZI $500 \mathrm{mg}$ initial dose and then $250 \mathrm{mg}$ daily for 5 days + HCQ loading dose of $400 \mathrm{mg}$ BID and then $200 \mathrm{mg} 3$ times a day (TID) for 5 to 10 days.

Before starting antiviral treatment, an EKG was routinely performed and repeated on a daily basis or more often if the patient was under treatment with a drug known to prolong the QT interval. Tocilizumab was used as an anti-inflammatory agent in those patients who fulfilled the following criteria: Patient with severe pneumonia and high interleukin-6 (IL-6) level (defined as a that greater of 40 $\mathrm{pg} / \mathrm{ml}$ ) as well as radiologic progression of pulmonary infiltrates or progressive respiratory failure or persistent elevation of C-reactive protein, D-Dimer or ferritin levels. Tocilizumab could be added to the antiviral treatment and the dose consisted of an IV dose of 400 $\mathrm{mg}$ in patients weighted below $75 \mathrm{~kg}$ or $600 \mathrm{mg}$ if weight was above $75 \mathrm{~kg}$ ) above. A second and final dose could be given according to clinical response (fever), oxygen needs and C-reactive protein level. Before the tocilizumab infusion was administered, patients had a complete assessment to discard active non-viral infection with serum procalcitonin, as well as, blood, respiratory and urine cultures. Also, several blood analyses were performed, such as HIV test, viral hepatitis panel and QuantiFERON-TB Gold. Patients could also receive antibiotics at their physician's discretion, this was most commonly ceftriaxone. All the patients or patients' relatives gave their informed consent for the compassionate use of antiviral drugs and tocilizumab.

\section{Anticoagulation and Thromboprophylaxis}

All patients were treated with enoxaparin as thromboprophylaxis at a $1 \mathrm{mg} / \mathrm{kg}$ once a day. If the patient had radiological evidence of pulmonary embolism or a D-dimer level above $3000 \mathrm{ng} / \mathrm{ml}$, enoxaparin was given at a $1 \mathrm{mg} / \mathrm{kg}$ twice daily. This guideline was made by a consensus of our group as many other centers recommend therapeutic-intensity anticoagulation in critically ill COVID-19 patients.

\section{Mechanical Ventilation}

We adhered to the Berlin definitions regarding the severity of respiratory failure, and if clinical situation required it, alternatives modalities were implemented, including the prone position [6]. 


\section{Statistical Analysis}

We used descriptive statistics expressed as numbers (percentages) for categorical variables. Continuous variables were expressed as mean and standard deviation $(\mathrm{SD})$ or median with interquartile range (IQR) values in accordance with their distribution. The Student's t-test or the Mann-Whitney tests were performed to compare the differences between the continuous variables according to their distribution. The Kolmogorov-Smirnov test was used as evidence of normality. Significant differences between categorical variables were evaluated using the Chi-square test. The ANOVA test was used to evaluate the differences between different treatment schemes and the length of stay. A p-value less than 0.05 was considered statistically significant. All statistical analyses were performed using SPSS version 22.0 (IBM Corp., Armonk, NY, USA).

\section{Results}

\section{Patient Characteristics}

We included all patients that were admitted to the COVID ward in the month following the first admission, which was on March 12th, 2020. All of them had severe or critical pneumonia. The clinical characteristics upon hospital arrival are depicted in Table 1. A total of
21 patients were classified in the severe pneumonia group (SPG) and 12 met criteria for the critical pneumonia group (CPG) during their hospitalisation. Most $(87.9 \%)$ of the patients had at least one positive nasopharyngeal RT-PCR for SARS-CoV2, whereas 4 patients had a negative RT-PCR though they had classical radiological and clinical characteristics for COVID-19 pneumonia.

Overall, the patients' mean age was 60.6 years (SD 12.68 years), and $23(70 \%)$ were males. The median duration of symptoms before admission was 7 (IQR 5-8) days. The most common symptoms were general malaise, $(84.8 \%)$ followed by fever (75.8\%) cough, $(63.6 \%)$ headache (42.4\%) and (24.2\%) diarrhoea. In a sub-group analysis for those who were RT-PCR negative, we found that diarrhoea was more common in this group compared to those with a positive RT-PCR ( $75 \%$ vs. $17.2 \%, \mathrm{p}<0.01$ ). One patient presented with rhabdomyolysis that was managed with aggressive fluid resuscitation. Twenty-three (70\%) patients had at least one comorbidity. Thirteen (39.3\%) patients were current smokers. Twenty-three (70\%) patients were overweight or obese. Twelve (35.3\%) patients had hypertension, and only 9 (27\%) were being treated with ACE or ARB drugs.

We found a higher BMI in the CPG compared to the SPG (26.3 \pm 3.4 vs. $30.1 \pm 6.1, \mathrm{p}<0.05$ ). Also, a greater proportion of patients in

Table 1: Clinical characteristics of the patients at admission and treatment given.

\begin{tabular}{|c|c|c|c|}
\hline & $\begin{array}{l}\text { Severe Pneumonia } \\
\mathbf{n}=\mathbf{2 1}\end{array}$ & $\begin{array}{c}\text { Critical Pneumonia } \\
n=12\end{array}$ & $\mathbf{p}$ \\
\hline Mean age & $57.6 \pm 13.2$ & $65.8 \pm 9.2$ & NS \\
\hline $\begin{array}{l}\text { Sex - n (\%) } \\
\text { Male } \\
\text { Female }\end{array}$ & $\begin{array}{c}14(66.7) \\
7(33.3) \\
\end{array}$ & $\begin{array}{l}9(75) \\
3(25)\end{array}$ & NS \\
\hline Mean body mass index & $26.3 \pm 3.4$ & $30.1 \pm 6.1$ & $<0.05$ \\
\hline $\begin{array}{l}\text { SARS-CoV2 positive RT-PCR } \\
\text { n (\%) }\end{array}$ & $18(85.7)$ & $11(91.7)$ & NS \\
\hline $\begin{array}{l}\text { Symptoms - n (\%) } \\
\text { Fever } \\
\text { Cough } \\
\text { Diarrhoea } \\
\text { Headache } \\
\text { Malaise }\end{array}$ & $\begin{array}{c}16(76.2) \\
13(61.9) \\
5(23.8) \\
8(38.1) \\
18(85.7)\end{array}$ & $\begin{array}{c}9(75) \\
8(66.7) \\
3(25) \\
6(50) \\
10(83.3)\end{array}$ & $\begin{array}{l}\text { NS } \\
\text { NS } \\
\text { NS } \\
\text { NS } \\
\text { NS }\end{array}$ \\
\hline Median respiratory rate (IQR) & $22(20-23)$ & $22(20-27)$ & NS \\
\hline Mean $\mathrm{PaO}_{2} / \mathrm{FiO}_{2}$ ratio & $207 \pm 25.1$ & $137 \pm 76.5$ & NS \\
\hline $\begin{array}{l}\text { Comorbidities - n (\%) } \\
\text { Any } \\
\text { Overweight or Obesity } \\
\text { Smoking } \\
\text { Hypertension } \\
\text { ACE or ARB treatment } \\
\text { Diabetes mellitus } \\
\text { Cardiopathy } \\
\text { COPD } \\
\text { Immunosuppression }\end{array}$ & $\begin{array}{c}12(57.1) \\
11(52.4) \\
7(33.3) \\
5(23.8) \\
3(14.3) \\
4(19) \\
2(9.5) \\
3(14.3) \\
1(4.7)\end{array}$ & $\begin{array}{c}11(91.7) \\
11(91.7) \\
6(50) \\
7(58.3) \\
6(50) \\
4(33.3) \\
1(8.3) \\
2(16.7) \\
1(50)\end{array}$ & $\begin{array}{l}<0.05 \\
<0.05 \\
\text { NS } \\
<0.05 \\
<0.05 \\
\text { NS } \\
\text { NS } \\
\text { NS } \\
\text { NS }\end{array}$ \\
\hline Mean duration of symptoms before admission - days (SD) & $7.6 \pm(4.3)$ & $6.3 \pm(1.9)$ & NS \\
\hline $\begin{array}{l}\text { Treatment }{ }^{*}-\mathbf{n}(\%) \\
\text { LPV/r + IFNb-1b + AZI } \\
\text { LPV/r + IFNb-1b + HCQ + AZI } \\
\text { LPV/r + HCQ + AZI } \\
\text { HCQ + AZI } \\
\text { Tocilizumab in addition to previous treatment }\end{array}$ & $\begin{array}{c}2(9.5) \\
6(28.6) \\
4(19) \\
9(42.9) \\
7(33.3)\end{array}$ & $\begin{array}{c}2(16.7) \\
3(25) \\
5(41.7) \\
2(16.7) \\
10(83.3)\end{array}$ & $\begin{array}{l}\text { NS } \\
\text { NS } \\
\text { NS } \\
\text { NS } \\
<0.05\end{array}$ \\
\hline
\end{tabular}

IQR: interquartile range, NS: not statistically significant, $\mathrm{PaO}_{2} / \mathrm{FiO}_{2}$ :, RT-PCR: reverse transcriptase-polymerase chain reaction.

${ }^{*} \mathrm{LPV} / \mathrm{r}$ : Lopinavir/ritonavir, IFNb 1b: Interferon beta-1b, HCQ: Hydroxychloroquine, AZi: Azithromycin. 
the CPG had comorbidities compared to those in the SPG $(91.7 \%$ vs. $57.1 \%, \mathrm{p}<0.05)$. Interestingly, hypertension and ACE or ARB treatment were also more common in the CPG. At admission, patients in the SPG had a higher $\mathrm{PaO}_{2} / \mathrm{FiO}_{2}$ ratio $(207 \pm 25.12$ vs. $137 \pm 76.45)$ compared to those in the CPG, though this difference was not significant. Of the 33 patients, thirty-one were also tested for influenza A/B by PCR or had a multiplex PCR panel for respiratory pathogens. Two patients were co-infected with influenza $\mathrm{A}$ and one with rhinovirus. All patients were started on antiviral treatment within the first 24 hours after admission once the diagnosis of COVID-19 pneumonia was confirmed. There were multiple combinations of antiviral therapy that are summarized as follows: four patients were treated with lopinavir/ ritonavir and interferon beta- $1 \mathrm{~b}$, and nine patients received this combination plus hydroxychloroquine. Another nine patients were prescribed lopinavir/ $\mathrm{r}$ and hydroxychloroquine, and eleven patients were treated with hydroxychloroquine monotherapy. All the patients were on azithromycin. There was no difference between the treatment options and the length of stay.

Tocilizumab was given to 17 (51.5\%) patients: $10(83.3 \%)$ patients in the CPG and 7 (33.3\%) in the SPG. On average, patients received tocilizumab $3.3 \pm 2.2$ days after admission. All patients did not have chronic viral hepatitis or HIV. All patients received enoxaparin for thromboprophylaxis.

\section{Laboratory and Radiologic Findings}

Laboratory and radiologic findings upon patients' arrival to the hospital are shown on Table 2. Troponin I and procalcitonin were significantly higher in CPG than in the SPG. Also, ferritin, lactic dehydrogenase and IL-6 levels were more elevated in CPG, however these differences were not statistically significant. All the patients had bilateral infiltrates in the computed tomography scan (CT-scan). Eleven (52.4\%) patients with severe pneumonia had bilateral groundglass infiltrates, while 9 (75\%) patients with critical pneumonia had bilateral mixed infiltrates (alveolar occupation and ground-glass infiltrates).

\section{Critical Pneumonia Group}

Twelve patients had critical pneumonia, 8/12 (66.6\%) patients had critical pneumonia or developed it in the first 48 hours after admission and4/12 (33.3\%) 48 hours after admission. All the critical patients required mechanical invasive ventilation. All the patients had at least one session of 16 hours of prone position in order to improve their $\mathrm{PaO} 2 / \mathrm{FiO} 2$.The median duration of the mechanical ventilation was 12 \pm 2.6 days. All the patients were extubated except one who required a tracheostomy. The patient who could not be extubated had previous chronic obstructive pulmonary disease (COPD). Among the 12 patients who had critical pneumonia, $10(83.3 \%)$ received tocilizumab.

\section{Complications}

We only documented two drug-related adverse reactions. One patient in the CPG stopped lopinavir/ritonavir on the fifth day because of a considerable increase in bilirubin (total bilirubin 6.6 $\mathrm{mg} / \mathrm{dl}$, direct bilirubin $4.5 \mathrm{mg} / \mathrm{dl}$ ) with normal alkaline phosphatase. After discontinuation, the bilirubin went back to normal within 3 days. Another patient in the CPG stopped azithromycin because of atrial fibrillation and a prolonged QT interval (468 mseg). Three patients developed ventilator-associated pneumonia with extended spectrum beta-lactamase Escherichia coli, non MDR Pseudomonas aeruginosa and Stenotrophomonas maltophilia. The deceased patient had Stenotrophomonas maltophilia infection. One patient

Table 2: Laboratory data at hospital admission and radiology findings.

\begin{tabular}{|c|c|c|c|}
\hline & Severe Pneumonia Patients $n=21$ & Critical Pneumonia Patients $n=12$ & $\mathbf{p}$ \\
\hline $\begin{array}{c}\text { White blood cell per } \mathrm{mm}^{3} \\
\text { Median (IQR) }\end{array}$ & $4.8(4-8.1)$ & $6.7(4.5-12.6)$ & NS \\
\hline $\begin{array}{c}\text { Lymphocyte count per } \mathrm{mm}^{3} \\
\text { Mean (SD) }\end{array}$ & $0.99(0.49)$ & $1.17(0.62)$ & NS \\
\hline $\begin{array}{l}\text { Creatinine } \mathrm{mg} / \mathrm{dL} \\
\text { Median }(\mathrm{SD})\end{array}$ & $0.98(0.39)$ & $1.21(0.46)$ & NS \\
\hline $\begin{array}{l}\text { Ferritin } \mathrm{mg} / \mathrm{dL} \\
\text { Median (IQR) }\end{array}$ & $930(407-1528)$ & $1341(398-2692)$ & NS \\
\hline Lactic dehydrogenase mg/dL Mean (SD) & $260.7(96.4)$ & $340.9(122.2)$ & NS \\
\hline $\begin{array}{l}\text { D-Dimer mg/dL } \\
\text { Mean (SD) }\end{array}$ & $802.4(451.2)$ & $939.9(407.2)$ & NS \\
\hline $\begin{array}{l}\text { Troponin I mg/dL } \\
\text { Median (IQR) }\end{array}$ & $5(3.5-9.1)$ & $17.3(7-29.3)$ & $<0.05$ \\
\hline $\begin{array}{c}\mathrm{IL}-6 \mathrm{mg} / \mathrm{dL} \\
\text { Median (IQR) }\end{array}$ & $47.4(21.6-92.3)$ & $173(46-231)$ & NS \\
\hline C-reactive protein mg/dL Mean (SD) & $8.38(7.82)$ & $13.34(9.53)$ & NS \\
\hline $\begin{array}{c}\text { Procalcitonin mg/dL } \\
\text { Mean (SD) } \\
\end{array}$ & $0.08(0.04-0.15)$ & $0.2(0.1-1.91)$ & $<0.05$ \\
\hline $\begin{array}{c}\text { CT findings }-\mathbf{n}(\%) \\
\text { Bilateral ground-glass opacification } \\
\text { Bilateral alveolar infiltrates } \\
\text { Bilateral mixed infiltrates (ground-glass and alveolar) }\end{array}$ & $\begin{array}{c}11(52.4) \\
1(4.8) \\
9(42.9)\end{array}$ & $\begin{array}{l}1(8.3) \\
2(16.7) \\
9(75)\end{array}$ & $<0.05$ \\
\hline
\end{tabular}

CT: computed tomography, IL6: interleukin-6, IQR: interquartile range, NS: not statistically significant, SD: standard deviation. 
developed invasive pulmonary aspergillosis, diagnosed by a positive galactomannan in bronchoalveolar lavage (BAL). This last patient with pulmonary aspergillosis, had a positive tuberculosis culture on BAL reported four weeks after being discharged. All the patients with bacterial or fungal positive cultures had received tocilizumab. Two patients developed subsegmental pulmonary emboli despite low-molecular-weight heparin thromboprophylaxis. One of them in each group. Two patients required re-intubation, one because of lifethreatening abdominal bleeding that required vascular surgery and the other one because of complete right lung atelectasis. Both patients were extubated in the next 72 hours after the bleeding and atelectasis resolved.

\section{Outcomes}

Table 3 depicts the major outcomes of our cases. All patients were followed up until hospital discharge or death. The median length of stay was 7 days (4.5-8.5) for the SPG and 25 days (22-33) for the CPG. All the patients in the SPG and 11 (91.6\%) patients in the CPG were discharged. Among the 12 patients who required invasive mechanical ventilation, only one died (8.3\%). The deceased patient was in his seventies, and suffered from hypertension, diabetes mellitus and moderate COPD. This patient required mechanical ventilation 48 hours after admission and was admitted after five days of illness. We were unable to progress mechanical ventilation, so he required a tracheostomy. The patient died 54 days after admission due to acute myocardial infarction and sepsis, in his late days he had ventilatorassociated pneumonia due to Stenotrophomonas maltophilia.

\section{Discussion}

This single-centre experience describes the epidemiology, treatment and outcome of 33 patients with severe or critical COVID-19 pneumonia admitted to the ICU and the high dependency unit during the first month at the beginning of the COVID-19 epidemics in Mexico. We found that most of our patients were overweight or obese males and had at least one comorbidity, similar to other reports [1,7]. Patients who required invasive mechanical ventilation had a high extubation rate despite a prolonged time of mechanical ventilation. Unexpectedly, we found a lower mortality rate (3\%) compared to other series of patients with severe and critical COVID-19 pneumonia. In our cohort, four patients (12\%) were RT-PCR negative for SARS$\mathrm{CoV}-2$, this finding is in agreement with previous reports that have shown that false-negative rate of oropharyngeal RT-PCR range from $10-40 \%$. RT-PCR sensitivity depends on several factors as days since the symptoms started, site of specimen collection and viral load [8]. We did not take any sample from BAL to perform RT-PCR because of the aerosolization risk and because initially those patients were not under mechanical ventilation. So, we could not compare the positivity from upper and lower respiratory tract samples.

The critical group had a higher prevalence of hypertension compared to the severe group, also a higher proportion of patients were under ACE or ARB treatment. This finding has previously been proposed as a risk factor to develop COVID-19 pneumonia, though there is little evidence to support this hypothesis $[9,10]$. Obesity and metabolic syndrome are chronic inflammatory diseases that make patients more prone to infectious complications and are known increase the mortality of COVID-19 [11]. In our case series, all but one of the patients in the critical group had overweight or were obese, and those in the critical group had a higher BMI compared to those in the severe group. The mean BMI in both groups was higher than those reported previously by Liu et al. [12]. This is an expected finding, since the prevalence of overweight and obesity in Mexico is one of the highest in the World, with $75.2 \%$ of the adult population living with a BMI above 25 [13]. The pathophysiology underlying the more severe clinical picture of COVID-19 in obese patients is linked to a chronic inflammatory and prothrombotic state, higher ACE2 concentrations in the alveolar epithelium plus a compromised pulmonary physiology [14]. Moreover, adipose tissue has been known to be a reservoir for some viruses, such as HIV and CMV, but its role as a tissue reservoir of SARS-CoV-2 remains to be studied [15]. Fever and cough were the most common presenting symptoms with a mean duration of 7 days before hospital admission, as previously reported in other series [16]. Patients in the critical group had a lower $\mathrm{PaO}_{2} / \mathrm{FiO}_{2}$ ratio at admission, but this difference was not statistically significant because some patients in the critical group had higher $\mathrm{PaO}_{2} / \mathrm{FiO}_{2}$ ratio at admission and later progressed to the critical phase. This is a well-known marker of serious respiratory illness [17].

Table 3: Outcomes.

\begin{tabular}{|c|c|c|c|}
\hline Characteristics & Severe Pneumonia Patients $n=21$ & Critical Pneumonia Patients $n=12$ & $\mathbf{p}$ \\
\hline Patients that progressed to critical pneumonia after 48 hours of admission - $\mathrm{n}(\%)$ & - & $4(33.3)$ & - \\
\hline $\begin{array}{c}\text { Maximum oxygen support during the hospital stay } \mathbf{n}(\%) \\
\text { Low-flow oxygen by nasal cannula and/or face tent } \\
\text { High-flow nasal cannula } \\
\text { Non-invasive positive pressure ventilation } \\
\text { Invasive mechanical ventilation }\end{array}$ & $\begin{array}{c}19(90.5) \\
2(9.5) \\
0(0) \\
0(0) \\
\end{array}$ & $12(100)$ & - \\
\hline Median length of stay - days (IQR) & $7(4.5-8.5)$ & $25(22-33)$ & $<0.05$ \\
\hline Vasopressor support (norepinephrine and/or vasopressin) - n (\%) & $0(0)$ & $10(83)$ & $<0.05$ \\
\hline Duration of mechanical ventilation in patients who were extubated Mean (IQR) - days & - & $12(9-15)$ & NS \\
\hline Extubated - n/total number (\%) & - & $11 / 12(91.6)$ & NS \\
\hline Discharged from hospital - n (\%) & $25(100)$ & $7(91.6)$ & NS \\
\hline Died in hospital - $\mathrm{n}(\%)$ & $0(0)$ & $1(8.3)$ & NS \\
\hline
\end{tabular}

IQR: interquartile range, NS: not statistically significant, SD: standard deviation. 
We found that ferritin and lactic dehydrogenase levels tend to be higher at baseline in patients with critical pneumonia at admission. As described in Chinese and Italian reports, higher ferritin and lactic dehydrogenase levels at admission were also significantly associated with critical pneumonia $[18,19]$. Moreover, we found a higher IL-6 concentration in patients with critical pneumonia. This finding has previously been reported by Chen X et al. [20]. Also, Interleukin- 6 has recently been proposed as an early predictor of respiratory failure in COVID-19 patients [21]. It is important to mention that the CPG had a significantly higher troponin I ( $\mathrm{cTnI}$ ) level at admission compared to the SPG. This finding has been described more commonly in sicker patients with an intense inflammatory response and it has been recognized as a biomarker to identify possible myocardial damage [22]. All of our patients were treated with different drug regimens with potential antiviral activity against SARS-CoV2. The medication was started within 24 hours of admission and around one week of symptom onset. Remarkably, tocilizumab was given to a half of our patient. The rationale for such a decision was based on observational data implicating the overwhelming systemic inflammatory cascade as a culprit in the physiopathology of this new and poorly understood disease and the plausible role for immunomodulation in these populations [23,24]. Regrettably, we did not find any effect of the administration of tocilizumab in the length of hospitalization and other outcome variables (data not shown). A recent report from Wadud $\mathrm{N}$ et al. described lower mortality in patients who received tocilizumab, and also a longer hospital stay compared to those who did not receive anti IL-6 therapy [25]. This, like in our experience, can probably be explained by the fact that critical patients who required mechanical ventilation are sicker and take longer time to recover. Currently, there are several ongoing clinical trials that will hopefully give us more answers regarding the role of tocilizumab in severe COVID-19. Nowadays, only a cohort study has reported the possible positive effect of this therapy [26].

All patients with critical COVID-19 pneumonia required mechanical ventilation with a mean duration of 12 days, similar to the report of critically ill patients in Seattle, where the duration of mechanical ventilation was 10 days, or in the New York City series, where the duration was 18 days [27,28]. Noteworthy is that our extubation rate was higher $(91.6 \%)$ than in other series. However, this is only our first month experience, patients arrived early and had access to a full intensive care support as at that point the hospital was not overwhelmed. Moreover, we had a fatality rate of $(8.3 \%)$ within patients who required invasive mechanical ventilation. This particular finding contrast with other series that have reported higher mortality, as the series from Cummings et al. in New York City with a fatality ratio of $39 \%$ or the Seattle series in which $50 \%$ of patients died $[27,28]$.

Regarding infectious complications, there were 3 cases of ventilatorassociated pneumonia and only one with a multidrug resistant bacteria, an extended spectrum beta-lactamase E. coli. Secondary bacterial infection has been related to longer hospital stays and worse outcomes [18]. Only one patient was diagnosed with probable invasive pulmonary aspergillosis, a fungal coinfection described in another reports [29]. Finally, with respect to viral coinfections, most of our patients were tested for other respiratory pathogens by molecular analysis, yet we only found only two patients with influenza and one with a rhinovirus coinfection. In contrast with other series that describe up to $20 \%$ of respiratory virus coinfection [30].

Pulmonary embolism was observed in two patients, despite receiving low molecular weight heparin thromboprophylaxis. Severe COVID-19 pneumonia can be complicated with prothrombotic coagulopathy, causing both major thromboembolic events and microthrombi in end-organ capillary beds. Therefore, it is currently recommended that all patients (unless contraindicated) should receive thromboprophylaxis, and those with elevated coagulation markers (specifically D-dimer) should receive full dose anticoagulation, as it appears to be associated with lower mortality. Our patients were managed following these recommendations, that have been associated with lower mortality [31,32]. Our study has several limitations: it is a small descriptive case series report, and there may be confounders in the analysis of the results, in concordance with most described data in the current literature. Another disadvantage is the lack of generalisability because out data in from a well-resourced hospital in Mexico City. However, the strength of this work is the fact that all patients were followed-up until discharge or death, so the current results on in-hospital mortality, extubation rate and outcome are not underestimated. Also, this to our best knowledge is the first series of well-characterised patients in a Mexican hospital. Our findings bring valuable information about the local epidemiology of severe and critical COVID-19 patients in lower-middle income countries.

\section{Acknowledgement}

The authors thank Aurora de la Peña and Carlos Cervera for important discussion and insights. Also, to all the residents and nurses from the ABC Medical Center.

\section{Funding}

The authors received no specific funding for the present work.

\section{References}

1. Guan WJ, Ni ZY, Hu Y, Liang WH, Ou CQ, et al. (2020) Clinical Characteristics of Coronavirus Disease 2019 in China. N Engl J Med 382: 1708-20.

2. Severe Outcomes Among Patients with Coronavirus Disease 2019 (COVID-19) - United States, February 12-March 16, 2020. MMWR Morb Mortal Wkly Rep 69: 343-6. [crossref]

3. National Health Commission of the Peoples Republic of China (2020). The diagnosis and treatment guide of COVID-19 pneumonia caused by new coronavirus infection. http://www.nhc.gov.cn/xcs/zhengcwj/202003/46c9294a7dfe4cef80dc7f5912eb1989. shtml

4. World Health Organization (2020). Clinical management of severe acute respiratory infection when novel coronavirus $(\mathrm{nCoV})$ infection is suspected: interim guidance. https://www.who.int/publications/i/item/clinical-management-of-severe-acuterespiratory-infection-when-novel-coronavirus-(ncov)-infection-is-suspected

5. Corman VM, Landt O, Kaiser M, Molenkamp R, Meijer A, et al. (2020) Detection of 2019 novel coronavirus (2019-nCoV) by real-time RT-PCR. Euro Surveill 25: 2000045. [crossref]

6. González MFJ, Salame KL, Olvera GCI, Valente AB, Aguirre SJ, et al. (2020) Posición prono en pacientes con síndrome de insuficiencia respiratoria progresiva aguda por COVID-19. Med Crítica 34: 73-77.

7. Wu C, Chen X, Cai Y, Xia J, Zhou X, et al. (2020) Risk Factors Associated With Acute Respiratory Distress Syndrome and Death in Patients With Coronavirus Disease 2019 Pneumonia in Wuhan, China. JAMA Intern Med 180: 934-943. 
8. Weissleder R, Lee H, Ko J, Pittet MJ (2020). COVID-19 diagnostics in context. Sci Transl Med 12: eabc1931.

9. Fang L, Karakiulakis G, Roth M (2020) Are patients with hypertension and diabetes mellitus at increased risk for COVID-19 infection? Lancet Respir Med 8: e21. [crossref]

10. Rico-Mesa JS, White A, Anderson AS (2020) Outcomes in Patients with COVID-19 Infection Taking ACEI/ARB. Curr Cardiol Rep 22: 31.

11. Peng YD, Meng K, Guan HQ, Leng L, Zhu RR, et al. (2020) [Clinical characteristics and outcomes of 112 cardiovascular disease patients infected by 2019-nCoV]. Zhonghua Xin Xue Guan Bing Za Zhi 48: 450-455. [crossref]

12. Liu M, He P, Liu HG, Wang XJ, Li FJ, et al. (2020) [Clinical characteristics of 30 medical workers infected with new coronavirus pneumonia]. Zhonghua jie he he hu xi za zhi 43: E016. [crossref]

13. Encuesta Nacional de Salud y Nutrición 2018 Ensanut. Available from: https:// ensanut.insp.mx/encuestas/ensanut2018/doctos/informes/ensanut_2018_ presentacion_resultados.pdf

14. Zhou P, Yang XL, Wang XG, Hu B, Zhang L, et al. (2020) A pneumonia outbreak associated with a new coronavirus of probable bat origin. Nature 579: 270-3. [crossref]

15. Bourgeois C, Gorwood J, Barrail-Tran A, Lagathu C, Capeau J, et al. (2019) Specific Biological Features of Adipose Tissue, and Their Impact on HIV Persistence. Front Microbiol 10: 2837. [crossref]

16. Wang D, Hu B, Hu C, Zhu F, Liu X, et al. (2020) Clinical Characteristics of 138 Hospitalized Patients With 2019 Novel Coronavirus-Infected Pneumonia in Wuhan, China. JAMA 323: 1061- 1069. [crossref]

17. Hudson LD, Milberg JA, Anardi D, Maunder RJ (1995) Clinical risks for development of the acute respiratory distress syndrome. Am J Respir Crit Care Med 151: 293-301. [crossref]

18. Zhou F, Yu T, Du R, Fan G, Liu Y, et al. (2020) Clinical course and risk factors for mortality of adult inpatients with COVID-19 in Wuhan, China: a retrospective cohort study. Lancet 395: 1054-62. [crossref]

19. Henry BM, de Oliveira MHS, Benoit S, Plebani M, Lippi G (2020) Hematologic, biochemical and immune biomarker abnormalities associated with severe illness and mortality in coronavirus disease 2019 (COVID-19): a meta-analysis. Clin Chem Lab Med 58: 1021-1028. [crossref]

20. Chen X, Zhao B, Qu Y, Chen Y, Xiong J, et al. (2020) Detectable serum SARS-CoV-2 viral load (RNAaemia) is closely correlated with drastically elevated interleukin 6 (IL-6) level in critically ill COVID-19 patients. Clin Infect Dis. https://doi.org/10.1093/cid/ciaa449
21. Herold T, Jurinovic V, Arnreich C, Hellmuth JC, von Bergwelt-Baildon M, et al. (2020) Level of IL-6 predicts respiratory failure in hospitalized symptomatic COVID-19 patients. medRxiv. Available from: http://medrxiv.org/content/ early/2020/04/10/2020.04.01.20047381.abstract

22. Lippi G, Lavie CJ, Sanchis-Gomar F (2020) Cardiac troponin I in patients with coronavirus disease 2019 (COVID-19): Evidence from a meta-analysis. Prog Cardiovasc Dis 63: 390-391. [crossref]

23. Mehta P, McAuley DF, Brown M, Sanchez E, Tattersall RS, et al. (2020) COVID-19: consider cytokine storm syndromes and immunosuppression. Lancet 395: 10331034

24. Xu Z, Shi L, Wang Y, Zhang J, Huang L, et al. (2020) Pathological findings of COVID-19 associated with acute respiratory distress syndrome. Lancet Respir Med 8: 420-422. [crossref]

25. Wadud N, Ahmed N, Shergil M, Khan M, Krishna M, et al. (2020) Improved survival outcome in SARs-CoV-2 (COVID-19) Acute Respiratory Distress Syndrome patients with Tocilizumab administration. medRxiv. https://www.medrxiv.org/ content/10.1101/2020.05.13.20100081v1.full.pdf

26. Xu X, Han M, Li T, Sun W, Wang D, et al. (2020) Effective treatment of severe COVID-19 patients with tocilizumab. Proc Natl Acad Sci 117: 10970-10975. [crossref]

27. Bhatraju PK, Ghassemieh BJ, Nichols M, Kim R, Jerome KR, et al. (2020) Covid-19 in Critically Ill Patients in the Seattle Region - Case Series. N Engl J Med 382: 2012 2022. [crossref]

28. Cummings MJ, Baldwin MR, Abrams D, Jacobson SD, Meyer BJ, et al. (2020) Epidemiology, clinical course, and outcomes of critically ill adults with COVID-19 in New York City: a prospective cohort study. Lancet 395: 1763-1770. [crossref]

29. Alanio A, Dellière S, Fodil S, Bretagne S, Megarbane B (2020) High prevalence of putative invasive pulmonary aspergillosis in critically ill COVID-19 patients. SSRN. Available from: https://ssrn.com/abstract=3575581

30. Kim D, Quinn J, Pinsky B, Shah NH, Brown I (2020) Rates of Co-infection Between SARS-CoV-2 and Other Respiratory Pathogens. JAMA 323: 2085-2086.

31. Kollias A, Kyriakoulis KG, Dimakakos E, Poulakou G, Stergiou GS, et al. (2020) Thromboembolic risk and anticoagulant therapy in COVID-19 patients: Emerging evidence and call for action. Br J Haematol 189: 846-847. Available from: http://doi. wiley.com/10.1111/bjh.16727

32. Barrett CD, Moore HB, Yaffe MB, Moore EE (2020) ISTH interim guidance on recognition and management of coagulopathy in COVID-19: A comment. J Thromb Haemost 18: 2060-2063 [crossref]

\section{Citation:}

Moreno-Sánchez F, Valente-Acosta B, Hoyo-Ulloa I, Espinosa-Aguilar L, Mendoza-Aguilar R, et al. (2021) COVID-19 Severe Pneumonia in Mexico City - First Experience in a Mexican Hospital. Infect Dis Ther Volume 2(1): 1-7. 